\title{
Certification of cause of death in French diabetic patients
}

\author{
B Balkau, L Papoz
}

\begin{abstract}
Study objective-The aim was to assess the level of mortality related to diabetes in France. In other countries, an underrecording of diabetes on the death certificates of diabetic patients has been reported.

Design and setting-Estimated death rate of diabetic patients was calculated using (a) the actual number of death certificates where diabetes was registered either as an underlying or as a contributory cause of death, and (b) estimates of the prevalence of diabetes in the population, by sex and age group, from which expected numbers of diabetic deaths were determined. Standardised mortality ratios were calculated using 1988 French mortality statistics as reference.
\end{abstract}

Main results-The estimated standardised mortality ratio for diabetic subjects, with diabetes registered as the underlying cause, was $0 \cdot 36$. This standardised mortality ratio increased to 0.92 if both the underlying and contributory causes were considered. The estimated death rate, by sex and age group, implies that diabetes has a protective effect between the ages of 45 and 64 years, particularly in men.

Conclusions-Evidence suggests that diabetes is completely omitted on the death certificates of many diabetic subjects, especially for those between the ages of 45 and 64 years. Using mortality statistics underestimates the prevalence of diabetes and its effects on public health. The difference in diabetes mortality between countries will not be reliable until there is a better registration of the causes of death in diabetic patients, and contributory as well as the underlying cause are coded and published.

The statistics on the underlying cause of death which are published in many countries provide a very inexpensive source of data and allow important trends and changes in causes of death (and by extrapolation the morbidity of various diseases) to be followed, both within and between countries. The reliability of these statistics has been questioned. ${ }^{1}$ Autopsy based and investigative studies in a number of countries indicate that their accuracy appears to be dependent on the particular cause of death of interest. $^{2-4}$

It has long been recognised that there is an excess mortality in diabetic subjects, mainly due to death from cardiovascular disease. ${ }^{56} \mathrm{~A}$ recent Canadian autopsy study ${ }^{7}$ found that circulatory disorders were the principal cause of death in $54 \%$ of diabetic men and in $59 \%$ of diabetic women. Tokuhata et $a l^{8}$ in 1975 described diabetes mellitus as an "underestimated health problem", this being due in part to the way diabetes was reported as a cause of death. Diabetic patients usually die from the complications of diabetes, thus diabetes does not always appear on the death certificate as the underlying cause of death. In the United States in 1979, diabetes was associated, on average, with 3.5 other causes of death, ${ }^{9}$ more than for the other causes cited. Diabetes was the underlying cause in only one out of five certificates where diabetes was registered as a cause. A 1980 Californian study gave consistent results, with a figure of $22 \% .{ }^{10}$ In Europe the figures are similar. The official 1986 mortality statistics from England and Wales indicated there were 31000 death certificates mentioning diabetes somewhere on the certificate. ${ }^{11}$ However, only one quarter of these gave diabetes as the underlying cause.

Prospective studies have been able to quantify this excess mortality. In a cohort of middle aged French diabetic men, followed for 15 years in comparison with normoglycaemic subjects, the relative risk for diabetic subjects of death from all causes was $2 \cdot 3(95 \%$ confidence interval: $1 \cdot 8-2 \cdot 9)$ and for death from ischaemic heart disease 1.5 $(0 \cdot 3-4 \cdot 6) .{ }^{12}$ In a study of British diabetic patients, the standardised mortality ratios for all cause mortality were 1.5 for men and 2.1 for women, and for ischaemic heart disease 1.9 and 2.7 respectively. ${ }^{13}$ Further, in this study of the death certificates of 2134 British diabetic subjects (one third of whom were diagnosed as diabetic before reaching 40 years of age), $18 \%$ had diabetes recorded as the underlying cause, a further $49 \%$ recorded diabetes as a contributory cause, but the remaining $33 \%$ had no mention of diabetes.

In many countries the contributory causes of death are not coded, and in other countries they are not published. France is one of the countries which, since 1968, has coded and published not only the underlying but also two contributory causes of death. ${ }^{14}$ There have been no published studies in France on the undercertification of death in diabetic subjects. We investigate here the death rates of diabetic subjects, using both the underlying and contributory causes of death.

\section{Methods}

French statistics for 1988 were used to give the population size and the numbers of deaths from diabetes and from all causes, by sex and by age 
group. Death from diabetes was obtained from the underlying cause and from the two contributory causes. Over this period the International classification of diseases, revision $9,{ }^{15}$ was used to code the causes of death; diabetes mellitus corresponds to the codes $250.0-250.9$, with the final digit indicating more precisely the cause of death.

The number of diabetic persons in the French population, by sex and age group, was estimated using the prevalence of diabetes of $1.9 \%$, from a 1974-5 survey, ${ }^{16}$ and the repartition of diabetes over sex and age groups, using the data from a 1985-6 study. ${ }^{17}$

The death rate for diabetic subjects was estimated using the actual number of deaths registered where diabetes was the underlying cause or a contributory cause, with the estimated number of diabetic subjects as denominator. The estimated diabetic death rate was then compared with that of the population death rate, by sex and age group, by taking the ratio.

In order to compare the mortality in the diabetic population with that in the general population, estimated standardised mortality ratios were calculated, using as reference the mortality rates in the French population in 1988; the standardised mortality ratio for diabetic subjects was estimated by the ratio of the observed number of diabetic deaths divided by the expected number of deaths (calculated using the estimated number of diabetic subjects by sex and age class and the corresponding population rates of death by all causes). ${ }^{18}$

\section{Results}

In France in 1988 there were 524500 deaths registered. Diabetes was recorded as the

Age and sex specific death rates $\times 10^{5}$ for deaths occurring in 1988, and the estimated standardised mortality ratios, where diabetes was mentioned as (1) an underlying cause or (2) any cause (underlying or contributory)

\begin{tabular}{|c|c|c|c|c|c|c|}
\hline \multirow{2}{*}{$\begin{array}{l}\text { Age } \\
\text { (years) }\end{array}$} & \multicolumn{3}{|c|}{ Underlying cause } & \multicolumn{3}{|c|}{ Any cause } \\
\hline & Men & Women & Both & Men & Women & Both \\
\hline $\begin{array}{l}<25 \\
25-34 \\
35-44 \\
45-54 \\
55-64 \\
65-74 \\
\geqslant 75\end{array}$ & $\begin{array}{l}0.030 \\
0.36 \\
1.5 \\
3.8 \\
13 \\
33 \\
110\end{array}$ & $\begin{array}{c}0.10 \\
0.21 \\
0.72 \\
1.9 \\
7.9 \\
29 \\
120\end{array}$ & $\begin{array}{l}0.067 \\
0.28 \\
1 \cdot 1 \\
2 \cdot 8 \\
10 \\
30 \\
115\end{array}$ & $\begin{array}{c}0 \cdot 080 \\
0 \cdot 78 \\
3 \cdot 2 \\
12 \\
43 \\
106 \\
290\end{array}$ & $\begin{array}{c}0.15 \\
0.43 \\
1 \cdot 3 \\
4 \cdot 8 \\
21 \\
74 \\
270\end{array}$ & $\begin{array}{c}0 \cdot 11 \\
0 \cdot 60 \\
2 \cdot 3 \\
8 \cdot 3 \\
32 \\
88 \\
280\end{array}$ \\
\hline $\begin{array}{l}\text { Estimate } \\
\text { SMR }^{\mathbf{a}}\end{array}$ & 0.21 & 0.56 & 0.36 & 0.59 & 1.34 & 0.92 \\
\hline
\end{tabular}

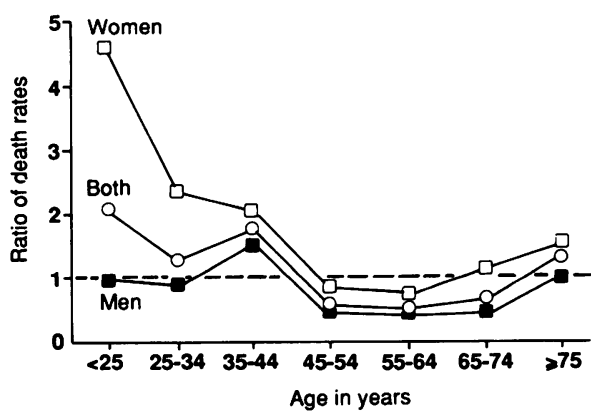

The 1988 data for the ratio of the estimated death rates of diabetic subjects with the death rates of the population, using both underlying and contributory causes, by sex and age classes. underlying cause in $1.3 \%$ of deaths, and as a contributory cause in a further $2.0 \%$.

The death rates due to diabetes, where diabetes was noted as underlying cause, or as any cause (underlying or first or second contributory cause), are shown in the table. They increased from a very low rate in those under 25 years; except for the very youngest and the oldest age groups, the rate was always greater in men than in women. For each sex and age class, the death rates when diabetes was the underlying cause were more than doubled when all causes were used, confirming that the use of only the underlying cause of death underestimates the contribution of diabetes as a cause of death

The ratio of the estimated death rate of diabetic subjects, with that of the general population, is shown in the figure. Before 45 years of age, the death rate was higher in diabetic subjects than in the general population, especially in women. For women under 25 years of age at death (who would mostly be type I diabetic subjects), the rate was 4.6 times higher than in the general population. For diabetic subjects between 45 and 64 years, diabetes appeared to protect against death, with the relative risk of death, in comparison with the general population, being as low as 0.4 in the 55-74 year old men. In the oldest age groups, in comparison with the general population, male diabetic subjects died at a similar rate, female diabetic subjects at a slightly higher rate.

The standardised mortality ratios (table), calculated on the basis of the estimated number of diabetic subjects and the number of diabetic deaths registered, indicated that as a whole diabetic subjects die at a rate lower than the general population, with the exception of women when both the underlying and contributing causes are taken into account. Similar results were obtained with the causes of death data for the years 1979, 1982, and 1985 .

\section{Discussion}

Monitoring the prevalence and/or the morbidity and mortality from diabetes, within and between countries, using the published figures reporting death from diabetes as the underlying cause, has severe restrictions. In France, using only the underlying cause under-records the mortality of diabetic subjects. Data from the Paris Prospective Study ${ }^{12}$ gave a relative risk of death from all causes of 2.3 for middle aged diabetic men in comparison to normoglycaemic men. In comparison, in this study the ratio of mortality rates was under 0.5 for this age group, even when the contributory causes of death were included. Thus the death rate of diabetic subjects may need to be doubled, trebled, or even quadrupled from that given by underlying and contributory causes to arrive at the true rate of death. The prevalence we have used in the calculations was conservative in view of the increasing prevalence of the disease ${ }^{19}$; a higher prevalence would further diminish the estimated standardised mortality rates and death rates of diabetic subjects.

The French death certificate ${ }^{14}$ differs from the international form of medical certification of cause of death. ${ }^{15}$ The underlying cause of death is the last cause certified in part I of the certificate; 
the international certificate has subsections $a, b$, and $c$, the French certificate has only a and b. Part II of the certificate, "other significant conditions contributing to the death", is identical. This should not alter international comparisons for either the underlying or contributory causes however the fact that there are three categories for the certification in part I may encourage the certifying physician to give more detail. The immediate cause of death, from part I of the certificate, is also coded in France, but it is rare for diabetes to be registered as the immediate cause.

White et $\mathrm{l}^{10}$ studied deaths where diabetes was mentioned on the death certificates for the years 1955 and 1980. In contrast to France, in California diabetes was more often mentioned on death certificates for women than for men. The highest death rate was in the 65-74 year old group, again in contrast to France, where the highest rates were in the age group over 75 years.

This study has found low estimated death rates for French diabetic subjects; this shows quite dramatically that diabetes is often not mentioned on the death certificate. The underdeclaration of diabetes as a cause of death in middle aged men may well be due to the fact that their death was ascribed to cardiovascular disease, although in diabetic subjects, diabetes perhaps should have been noted as a contributing factor. The recording of diabetes may be a little more accurate for women, as cardiovascular disease is less common, and its presence may be linked more readily with diabetes by the certifying physician.

The certification of cause of death is a complex process in which there are a number of stages, each of which can lead to a diabetic patient not having diabetes recorded on his death certificate. Firstly, it depends on whether the patient had been diagnosed as diabetic (which depends on the general health care and screening), secondly on whether the certifying physician knows the clinical history of the deceased, thirdly on his diagnosis, and fourthly on the part that diabetes played in the death; finally, the underlying (and contributory) cause(s) registered depend on the nosologist(s) who codes the cause(s) of death according to the International classification of diseases rules. There may be a number of nosologists who code the certificates; in France the variability between nosologists should be low, as all coding is performed centrally.

We can reiterate the comments of Comstock and Markush ${ }^{20}$ and Kircher and Anderson ${ }^{21}$ on the problems inherent in the certification of the cause of death. Physicians have little or no training in filling out these certificates, they often do not realise their importance in epidemiological research, and they may see them as only a legal formality, required before funeral arrangements can be made. Lindahl et $e^{22}$ recently provided suggestions on ways in which the WHO instructions on the completion of death certificates could be improved. They also recommended that all causes contributing to the death should be included in the coding process, and not just the underlying cause. Between country comparisons can only be reliable if the data within each country are improved, and all possible sources of error are removed.

With an aging population, diabetes is becoming more prevalent and will have an even greater significance in terms of public health. Its importance should not be judged merely on the death rates published, particularly if only the underlying cause of death is noted.

We would like to thank Eric Jougla for his advice about the methodology of certification and codification of causes of death in France and also a referee who provided us with data from England and Wales.

1 Moriyama IM. Problems in measurement of accuracy of cause-of-death statistics. Am $\mathcal{F}$ Public Health 1989; 79: 1349-50.

2 Abramson JH, Sacks MI, Cahana E. Death certification data as an indication of the presence of certain common diseases at death. $\mathcal{f}$ Chron Dis 1971; 24: 417-31.

3 Hasuo $Y$, Ueda K, Kiyohara Y, et al. Accuracy of diagnosis on death certificates for underlying causes of death in a long-term autopsy-based population study in Hisayama, Japan; with special reference to cardiovascular diseases. $\mathcal{F}$ Japan; with special reference to car

4 Benavides FG, Bolumar F, Peris R. Quality of death certificates in Valencia, Spain. Am $\mathcal{F}$ Public Health 1989; 79: certificates

5 West KW. Epidemiology of diabetes and its vascular lesions. New York: Elsevier, 1978.

6 O'Sullivan JB, Mahan CM. Mortality related to diabetes and blood glucose levels in a community study. Am $\mathcal{F}$ Epidemiol 1982; 116: 678-84

7 Joron GE, Laryea E, Jaeger D, Macdonald L. Causes of death in 1144 patients with diabetes mellitus: an autopsy study. Can Med Assoc F 1986; 134: 759-64.

8 Tokuhata GK, Miller W, Digon E, Hartman T. Diabetes mellitus: an underestimated public health problem. $f$ Chron Dis 1975; 28: 23-35.

9 Israel RA, Rosenberg HM, Curtin LR. Analytical potential for multiple cause-of-death data. Am $\mathcal{F}$ Epidemiol 1986; 124: 161-79.

10 White MC, Selvin S, Merrill DW. A study of multiple causes of death in California: 1955 and 1980. I Clin Epidemiol 1989; 42: 355-65.

11 Mortality statistics: cause 1986 (series $\mathrm{DH} 2$ no. 13). London: Office of Population and Censuses and Surveys, 1988.

12 Balkau B, Eschwège E, Ducimetière $P$, Richard J-L, Warnet J-M. The high risk of death by alcohol related diseases in subjects diagnosed as diabetic and impaired glucose tolerant: the Paris Prospective Study after 15 years glucose tolerant: the Paris Prospective Study after
of follow-up. $\mathcal{f}$ Clin Epidemiol 1991; 44: 465-74.

13 Fuller JH, Elford J, Goldblatt P, Adelstein AM. Diabetes mortality: new light on an underestimated public health mortality: new light on an underestimate

14 Lion J, Hatton F, Maguin P, Maujol L. Statistiques des causes médicales de décés. Paris: Editions INSERM, 1985. causes medicales de deces. Paris: Editions INSERM, 1985.
World Health Organization. International classification of diseases, 9th revision. Geneva: WHO, 1977.

diseases, 9th revision. Geneva: WHO, 1977.
Colvez A, Eschwège E, Michel E, Hatton F. Le diabète en médecine libérale. Données de l'enquête nationale INSERM sur la médecine libérale. (1974-1975). Diabete Metab 1983; 9: 69-74.

17 Papoz L, Vauzelle F, Vexiau P, Cathelineau G. Pattern of treatment among diabetic patients in France. Diabetes Care 1988: 11: 586-91.

18 Armitage P, Berry G. Statistical methods in medical research. 2nd ed. Oxford: Blackwell Scientific Publications, 1987.

19 Fontbonne A, Papoz L, Eschwège E. Drug sales data and prevalence of diabetes in France. Rev Epidemiol Sante Publique 1986; 34: 100-5.

20 Comstock GW, Markush RE. Further comments on problems in death certification. Am $\mathcal{F}$ Epidemiol 1986; 124:

21 Kircher T, Anderson RE. Cause of death. Proper completion of the death certificate. $\mathcal{F} A M A$ 1987; 258 : 349-52.

22 Lindahl BIB, Glattre E, Lahti R, Magnusson G, Mosbech J. The WHO principles for registering causes of death: suggestions for improvement. $\mathcal{F}$ Clin Epidemiol 1990; 43: 467-74. 